\title{
QUALIDADE DE SEMENTES DE QUATRO CULTIVARES DE SOJA, COLHIDAS EM DOIS LOCAIS NO ESTADO DO MATO GROSSO DO SUL ${ }^{1}$
}

\author{
ANDRÉIA MINUZZI2; ALESSANDRO DE LUCCA E BRACCINI ${ }^{3}$; MARCO ANTÔNIO SEDREZ RANGEL4; \\ CARLOS ALBERTO SCAPIM ${ }^{3}$; MAURO CEZAR BARBOSA ${ }^{2 *}$; LEANDRO PAIOLA ALBRECHT²
}

\begin{abstract}
RESUMO - $O$ trabalho foi realizado com objetivo de avaliar a qualidade das sementes de quatro cultivares de soja (BRS 133, BRS 206, BRS 239 e CD 202), colhidas em quatro épocas (Estádio R $\mathrm{R}_{7} \mathrm{e}$ 7, 14 e 21 dias após a primeira época) e produzidas em dois locais do Estado do Mato Grosso do Sul (Sidrolândia e Dourados), nos anos agrícolas de 2004/05 e 2005/06. O delineamento experimental utilizado foi em blocos casualizados com três repetições e tratamentos arranjados no esquema de parcelas subdivididas. As parcelas foram constituídas pelas cultivares de soja e as subparcelas pelas épocas de colheita. A germinação foi avaliada pelo teste de germinação; teste de envelhecimento acelerado e o vigor pelo teste de frio sem solo, teste de emergência das plântulas em substrato de areia e teste de sanidade. Os dados coletados nos diferentes locais foram submetidos à análise de variância conjunta de parcelas subdivididas e, na presença de interação significativa, foram realizados os desdobramentos necessários para os dois anos agrícolas, separadamente. No ano agrícola 2004/05, as cultivares BRS 239 e CD 202 apresentaram-se com elevada porcentagem de germinação para a produção de sementes na região de Dourados. No ano agrícola 2005/06, a cultivar BRS 239 foi a que apresentou melhor germinação e vigor. A cultivar BRS 239 apresenta menor índice de infecção de microrganismos em relação a cultivar BRS 206. Melhor qualidade de sementes é obtida das sementes colhidas aos sete dias após o estádio $\mathrm{R}_{7}$. Em relação à qualidade sanitária das sementes, à medida que se retarda a época de colheita, a porcentagem total de microrganismos aumenta linearmente para todas as cultivares.
\end{abstract}

Termos para indexação: Glycine max, germinação, vigor, retardamento da colheita.

\section{SEED QUALITY OF FOUR SOYBEAN CULTIVARS, HARVESTED IN TWO LOCATIONS OF MATO GROSSO DO SUL STATE}

\begin{abstract}
The object of this study was to evaluate the seed quality of four soybean cultivars (BRS 133, BRS 206, BRS 239 and CD 202), harvested at four different times (R7 stage and 7, 14 and 21 days after the first period), at two locations in Mato Grosso do Sul state, Brazil (Sidrolândia and Dourados), in the 2004/05 and 2005/06 crop seasons. The experimental design was a randomized
\end{abstract}

\footnotetext{
${ }^{1}$ Submetido em 25/10/2008. Aceito para publicação em 15/06/2009.

${ }^{2}$ Pos-graduandos da Universidade Estadual de Maringá, Paraná. Pósgraduação em Agronomia-PGA. Av. Colombo 5790, Bloco J-45, CEP:87020-900. Maringá, PR. E-mail: andminuzi@zipmail.com.br; mcezarbarbosa@yahoo.com.brelpalbrecht@yahoo.com.br.
}

${ }^{3}$ Docentes da Universidade Estadual de Maringá, Departamento de Agronomía. Av. Colombo 5790, Bloco J-45, CEP:87020-900. Maringá, PR. E-mail: albraccini@uem.br; cascapim@uem.br.

${ }^{4}$ Empresa de Pesquisa Agropecuária, EMBRAPA Agropecuária Oeste, Caixa Postal 661, CEP 79804-970, Dourados, MS. E-mail: rangel@cpao. embrapa.br. 
block with three replications in a split-plot. The plots and subplots were composed of soybean cultivars and harvest periods, respectively. Germination was evaluated by the standard germination test and vigour by the cold test without soil, the test of seedling emergence in a sand substrate, accelerated aging test and also by the health test. The data collected at the different sites were submitted to an analysis of variance of the split plots and, in the presence of significant interaction, the data were separated for the two crop years. In the 2004/ 2005 crop season, the BRS 239 and CD 202 soybean varieties showed high percentage germination for the production of seeds in the Dourados area. The best seed quality was obtained by harvesting 7 days after the R7 stage. BRS 239 showed less infection by microorganisms compared to cultivar BRS. In the 2005/ 2006 crop season, the BRS 239 cultivar showed the best germination and vigour. In relation to seed health quality, with greater delays in harvesting, the total percentage of microorganisms increases linearly for all the cultivars.

Index terms: Glycine max, germination, vigour, late harvest.

\section{INTRODUÇÃO}

A cultura da soja, introduzida no Brasil no final do século XIX, teve expansão nas últimas três décadas com aumento considerável da área de cultivo, principalmente em decorrência do lançamento de novas cultivares mais adaptadas a diversas regiões e mais produtivas (Embrapa Soja, 2006; Coodetec, 2006; Priolli et al., 2004). O estudo de interações entre diferentes ambientes e genótipos de soja tem sua importância no conhecimento da adaptação de linhagens e cultivares a um determinado ambiente e da sua estabilidade de produção ao longo dos anos, principalmente para fins de recomendação de cultivares. Nos últimos anos, elevados índices de produtividade de soja têm sido alcançados, no Brasil, especialmente nas regiões Sudeste e Centro-Oeste. Entretanto, diversos fatores têm limitado a obtenção de sementes de qualidade fisiológica e sanitária satisfatórias em algumas regiões do país.

França Neto et al. (2007) relatam a influência da cultivar, das condições de campo, de armazenagem, dos patógenos e da época de colheita na qualidade da semente de soja. A qualidade fisiológica de lotes de sementes é avaliada, rotineiramente, pelo teste de germinação, cujos resultados correlacionam-se, em geral, com a emergência de plântulas em condições favoráveis no campo. Entretanto, se as condições de campo, na época de semeadura forem desfavoráveis, o teste de germinação tenderá à imprecisão. Nesses casos, segundo Marcos Filho et al. (1987), os testes de vigor são mais úteis para prever o desempenho das sementes no campo.

O aumento da demanda por produtos de soja provocou expansão rápida do cultivo para áreas mais quentes e úmidas, características de regiões tropicais. Todavia, temperaturas e umidades relativas elevadas em ambientes tropicais e subtropicais tornam difícil a produção de semente de soja de boa qualidade e a manutenção do vigor durante o armazenamento.

Após a maturação fisiológica, as sementes são consideradas como armazenadas em campo, enquanto não é realizada a colheita (Costa et al., 1983). O retardamento da colheita da soja, após a maturidade fisiológica, pode causar reduções de germinação e do vigor das sementes dependentes de fatores genéticos e das condições do ambiente natural às quais estão expostas.

O trabalho foi realizado com objetivo de avaliar a qualidade das sementes de quatro cultivares de soja, colhidas em quatro épocas, em duas localidades do Estado do Mato Grosso do Sul e em dois anos agrícolas.

\section{MATERIAL E MÉTODOS}

$\mathrm{O}$ experimento de campo foi instalado em áreas localizadas nos municípios de Sidrolândia-MS, pertencente à Fazenda Recanto e de Dourados - MS, pertencente a Sementes Guerra S/A, nos anos agrícolas de 2004/05 e 2005/06, cujos solos são caracterizados como Latossolo Vermelho distroférrico (Embrapa, 1999). Na adubação de plantio foram empregados, nos anos agrícolas e localidades, $400 \mathrm{~kg} \cdot \mathrm{ha}^{-1}$ da fórmula 2-20-20. A semeadura foi efetuada de forma direta, em palhada de aveia, cultivada no período de inverno e dessecada com Glyphosate, na dosagem de 4 L.ha ${ }^{-1}$, 30 dias antes da semeadura da soja.

A semeadura das cultivares, CD 202, BRS 239, BRS 206 (ciclos precoces) e BRS 133 (ciclo semiprecoce) foi 
realizada no segundo decêndio de novembro, duas semanas após a emergência das plântulas, com desbastes para aproximadamente14 plantas por metro (população de 311.111 plantas.ha $\left.\mathrm{a}^{-1}\right)$. As sementes foram previamente tratadas com fungicidas à base de Carboxin + Thiram, na dosagem de 250 $\mathrm{mL}$ do produto comercial $+250 \mathrm{~mL}$ de água para $100 \mathrm{~kg}$ de sementes, e também inoculadas com inoculante turfoso à base de Bradyrhizobium japonicum. Tanto em Sidrolândia como em Dourados, os tratos culturais foram realizados conforme as recomendações para a região até o final do ciclo da cultura (Embrapa Soja, 2006).

As parcelas (cultivares de soja) foram constituídas de oito fileiras de 10 metros de comprimento, espaçadas de 0,45 $\mathrm{m}$ entre si. Na colheita das subparcelas (épocas de colheita), foram eliminadas as fileiras externas, bem como $2,5 \mathrm{~m}$ de cada extremidade das fileiras centrais como bordaduras, e colhidas parcelas de duas fileiras com cinco metros de comprimento. A colheita foi realizada em quatro épocas: no estádio $\mathrm{R}_{7}$ e aos sete, 14 e 21 dias após a 1ㄹépoca. A área útil das unidades foi de $4,5 \mathrm{~m}^{2}$.

Os dados de precipitação pluvial, de temperaturas máximas e mínimas diárias e de umidades relativas do ar, referentes aos períodos de duração do experimento no campo, em ambos as localidades e anos agrícolas, coletados diariamente, são apresentados na Figura 1.

A qualidade fisiológica e sanitária foi avaliada empregando-se testes de germinação e de vigor (testes de emergência de plântulas em areia, de frio sem solo e de envelhecimento acelerado) e pelo método do papel filtro "blotter test", respectivamente descritos a seguir:

Teste de germinação: foi conduzido utilizando-se quatro subamostras de 50 sementes, para cada repetição, colocadas em papel germiteste, umedecidas com água destilada utilizando-se 2,5 vezes a massa do papel seco embebido em água. Acondicionados no germinador e regulado para manter a temperatura constante de $25{ }^{\circ} \mathrm{C}$. As avaliações foram realizadas aos cinco (primeira contagem) e oito dias (contagem final), computando-se a porcentagem de plântulas normais, segundo os critérios estabelecidos pelas Regras para Análise de Sementes (Brasil, 1992).

Teste de emergência das plântulas em areia: foi conduzido com quatro subamostras de 50 sementes para cada tratamento e repetição. A areia utilizada foi esterilizada e colocada em bandejas plásticas. $\mathrm{O}$ teste foi realizado em condições de casa de vegetação e a umidade mantida com irrigações moderadas. Quando as plântulas começarem a emergir, foi realizada irrigação mais constante para facilitar o rompimento da camada de areia. Foram efetuadas anotações diárias do número de plântulas emergidas até que este número manteve-se constante. Os resultados foram expressos em porcentagem de plântulas normais, conforme as prescrições contidas nas Regras para Análises de Sementes (Brasil, 1992).

Teste de frio sem solo: foi realizado com quatro subamostras de 50 sementes por tratamento e repetição, em papel germiteste previamente umedecido em água destilada, na proporção de três vezes a massa do papel seco. Os rolos confeccionados foram envoltos por sacos plásticos e lacrados com fita adesiva, permanecendo nessa condição por um período de cinco dias em câmara de germinação do tipo B.O.D., à temperatura constante de $10^{\circ} \mathrm{C}$. Ao término desse período, os rolos foram retirados dos sacos plásticos e levados para germinador regulado a $25^{\circ} \mathrm{C}$, durante quatro dias. Posteriormente, foi realizada a avaliação computandose o número de plântulas normais (Barros et al., 1999). Os resultados foram expressos em porcentagem de plântulas normais, segundo os critérios adotados para o teste de germinação (Brasil, 1992).

Teste de envelhecimento acelerado: conduzido com quatro subamostras de 50 sementes por tratamento e repetição, as quais foram dispostas sobre tela de aço inox inserida no interior de caixas plásticas do tipo "gerbox", contendo $40 \mathrm{~mL}$ de água. A umidade relativa no interior das caixas plásticas foi de aproximadamente $100 \%$, conforme a metodologia descrita por Krzyzanowski et al. (1991). Posteriormente, as caixas foram levadas a uma câmara de germinação do tipo B.O.D., regulada para manter constante a temperatura de $41^{\circ} \mathrm{C}$, por 48 horas. Após o período de envelhecimento, as sementes foram submetidas ao teste de germinação descrito anteriormente e a avaliação foi realizada no quinto dia após a semeadura, computando-se as plântulas consideradas normais (Marcos Filho, 1999).

Teste de sanidade: efetuado pelo método do papel-filtro ou "blotter test", utilizando-se 100 sementes, divididas em quatro subamostras de 25 e colocadas em caixas plásticas do tipo "gerbox", sobre quatro folhas de papel-filtro esterilizadas e umedecidas com água destilada e autoclavada. A incubação foi realizada em condição ambiente de laboratório, à temperatura de aproximadamente $25{ }^{\circ} \mathrm{C}$, em regime de 12 horas de iluminação com lâmpadas fluorescentes, alternadas com 12 horas de escuro, durante sete dias. Após esse período, foram avaliados os fungos presentes nas sementes, com o auxílio de lupa com iluminação e microscópio estereoscópico (Henning, 1994; Goulart, 1997).

O delineamento experimental foi em blocos casualizados com três repetições de campo e tratamentos arranjados no esquema de parcelas subdivididas. As parcelas corresponderam as quatro cultivares de soja (BRS 
133, BRS 206, BRS 239 e CD 202), e as subparcelas as quatro épocas de colheita $\left(R_{7}\right.$, sete, quatorze e vinte e um dias após a primeira época), considerando as localidades (Dourados e Sidrolândia - MS) e os anos agrícolas 2004/05 e 2005/06. Os dados foram submetidos à análise de variância conjunta de parcelas subdivididas e, quando constatada interação significativa, foram realizados os desdobramentos necessários. As médias das cultivares de soja foram comparadas pelo teste de Tukey a 5\% de probabilidade. A análise de regressão foi utilizada para verificar o comportamento das características qualitativas e sanitárias, em função das épocas de colheita, para cada genótipo. Para o efeito de local, o teste F foi conclusivo, com apenas um grau de liberdade.

\section{RESULTADOS E DISCUSSÃO}

\section{Ano agrícola 2004/05}

A análise de variância conjunta das características avaliadas revelou efeito significativo $(\mathrm{P}<0,05)$ apenas dos fatores principais para cultivar (germinação e sanidade) e épocas de colheita (emergência em areia e sanidade) e da interação de primeira ordem localidade x cultivar (germinação e emergência em areia); cujo desdobramento é apresentado na Tabela 1.

TABELA 1. Médias de germinação (GER) e de emergência de plântulas em areia (EPA) de sementes de quatro cultivares de soja em duas localidades de produção no Estado do Mato Grosso do Sul, ano agrícola de 2004/05.

\begin{tabular}{|c|c|c|c|}
\hline \multirow{2}{*}{ Características } & \multirow{2}{*}{ Cultivar $^{1}$} & \multicolumn{2}{|c|}{ Local $^{2}$} \\
\hline & & Sidrolândia & Dourados \\
\hline \multirow{7}{*}{ GER (\%) } & BRS 133 & 78 a $\mathrm{A}$ & $76 \mathrm{~b} \mathrm{~A}$ \\
\hline & BRS 206 & $69 \mathrm{c} \mathrm{A}$ & $72 \mathrm{c} \mathrm{A}$ \\
\hline & BRS 239 & $71 \mathrm{bB}$ & 83 a A \\
\hline & CD 202 & $67 \mathrm{c} \mathrm{B}$ & 80 a A \\
\hline & Média & 71 & 78 \\
\hline & C.V.(\%) Erro 1 & 6,6 & \\
\hline & C.V.(\%) Erro 2 & 3,4 & \\
\hline \multirow{7}{*}{$\mathrm{EPA}(\%)$} & BRS 133 & 78 a A & $77 \mathrm{~b} \mathrm{~A}$ \\
\hline & BRS 206 & $69 \mathrm{c} \mathrm{A}$ & $73 \mathrm{c} \mathrm{A}$ \\
\hline & BRS 239 & $71 \mathrm{~b} \mathrm{~B}$ & 84 a A \\
\hline & CD 202 & $68 \mathrm{c} \mathrm{B}$ & 80 a A \\
\hline & Média & 72 & 78 \\
\hline & C.V.(\%) Erro 1 & 5,7 & \\
\hline & C.V.(\%) Erro 2 & 3,1 & \\
\hline
\end{tabular}

${ }^{1}$ Médias seguidas de mesma letra minúscula na coluna não diferem entre si pelo teste de Tukey, a 5\% de probabilidade.

${ }^{2}$ Médias seguidas de mesma letra maiúscula na linha não diferem entre si pelo teste $\mathrm{F}$, a $5 \%$ de probabilidade.

Considerando o local de produção Sidrolândia foi verificada qualidade fisiológica superior, pelos testes de germinação e de emergência de plântulas em areia, nas sementes da cultivar BRS 133 em relação às demais, e da BRS 239 em relação à BRS 206 e CD 202; essas cultivares apresentaram comportamento inferior para germinação e emergência em areia. Na localidade de Dourados, as sementes das cultivares BRS 239 e CD 202 mostraram-se superiores às das cultivares BRS 133 e BRS 206, com porcentagens de germinação adequada $(\geq 80 \%)$. Na comparação entre os locais, foi verificado que as sementes das cultivares BRS 239 e CD 202 mostraram-se com germinação superior em
Dourados e para as demais cultivares, não houve diferença significativa entre os locais.

Os baixos valores de porcentagem de germinação, provavelmente, devem-se a ocorrência de temperaturas elevadas $\left(>30^{\circ} \mathrm{C}\right)$ e a falta de chuva durante o período de enchimento de grãos (fase crítica), sendo a cultura da soja extremamente exigente em temperatura (em torno de $22{ }^{\circ} \mathrm{C}$ $\left.-27^{\circ} \mathrm{C}\right)$ e disponibilidade hídrica $(7-8 \mathrm{~mm} /$ dia na fase crítica) para bom desenvolvimento e boa qualidade de semente (Farias et al., 2007; Garcia et al., 2007).

Em relação à qualidade sanitária (Tabela 2), menor incidência de microrganismos foi observada em sementes da 
cultivar BRS 239, razão possível para o maior porcentual de germinação verificado no teste de germinação. A cultivar BRS 206 também apresentou relação inversa entre presença de microrganismos e porcentagem de germinação, apresentando alta porcentagem de infecção por patógenos e menor porcentual de germinação. Vários autores referiram-se à sanidade das sementes como um dos fatores preponderantes no desempenho das sementes e outros, ainda, relacionaram a qualidade sanitária com as condições climáticas reinantes nas fases finais da cultura, como alta temperatura e precipitação (Pereira et al., 2000; Braccini et al., 2003a,b; Marcos Filho, 2005; Garcia et al., 2007; Albrecht et al., 2008). O processo deteriorativo das sementes acarreta menor qualidade, associando sanidade e desempenho fisiológico, considerando uma relação em que os patógenos podem afetar o vigor das sementes, mas, por outro lado, o baixo vigor de sementes decorrente de fatores não-infecciosos, pode predispor as sementes à ação mais severa de patógenos (Machado, 1988; Marcos Filho, 2005; Albrecht et al., 2008).

TABELA 2. Médias de germinação (GER) e incidência de microrganismos (SAN) de sementes de quatro cultivares de soja produzidas no Estado do Mato Grosso do Sul, ano agrícola de 2004/05.

\begin{tabular}{lcc}
\hline \multirow{2}{*}{ Cultivar } & \multicolumn{2}{c}{ Características } \\
\cline { 2 - 3 } & GER $(\%)$ & SAN $(\%)$ \\
\hline BRS 133 & $77 \mathrm{a}^{1}$ & $18 \mathrm{bc}$ \\
BRS 206 & $70 \mathrm{c}$ & $21 \mathrm{a}$ \\
BRS 239 & $77 \mathrm{a}$ & $15 \mathrm{c}$ \\
CD 202 & $73 \mathrm{~b}$ & $19 \mathrm{ab}$ \\
\hline Média & 74 & 18 \\
\hline C.V.(\%) Erro 1 & 6,6 & 21,1 \\
\hline C.V.(\%) Erro 2 & 3,4 & 6,4 \\
\hline
\end{tabular}

${ }^{1}$ Médias seguidas de mesma letra na coluna, não diferem entre si pelo teste de Tukey, a 5\% de probabilidade.

A análise de regressão dos resultados da porcentagem de plântulas normais no teste de emergência de plântulas em areia, em função das épocas de colheita (Figura 2), indicou melhor ajuste do modelo quadrático, com ponto de máximo aos sete dias após o estádio $\mathrm{R}_{7}(78,74 \%)$. Reduções de vigor foram verificadas em sementes colhidas após o referido estádio, indicativo, portanto, de prejuízos à sua capacidade de produzir plântulas normais. Esses resultados são consonantes aos referidos por Nakagawa et al. (1985) que verificaram efeito negativo acentuado da qualidade de sementes de soja na emergência de plântulas, decorrente do baixo vigor por retardamento de colheita.

Semente de baixa qualidade, aliada às condições ambientais adversas por ocasião da semeadura, pode causar reduções da porcentagem de germinação e da velocidade de emergência das plântulas. Por outro lado, germinação mais rápida e uniforme é apresentada por sementes de alto vigor, com capacidade, inclusive, de melhor suportar as adversidades do local (Lopes et al., 2002).

$\mathrm{O}$ estádio considerado para colheita da soja é o $R_{8}$. Porém, antes desta fase, é atingida a maturidade fisiológica das sementes no estádio reprodutivo $\mathrm{R}_{7}$, caracterizado pelo máximo vigor e germinação; entretanto, o grau de umidade das sementes, de aproximadamente 30 a $40 \%$, dificulta ou impossibilita a operação de colheita mecânica em virtude dos danos físicos às sementes e à grande quantidade de folhas (Lacerda et al., 2003).

\section{Ano agrícola 2005/06}

A análise de variância conjunta das características avaliadas revelou efeito significativo $(\mathrm{P}<0,05)$ apenas dos fatores isolados localidade (germinação e sanidade), cultivar (germinação, envelhecimento acelerado e emergência em areia) e épocas de colheita (frio sem solo). Foi verificado efeito significativo para a interação de primeira ordem cultivar $\mathrm{x}$ épocas de colheita (sanidade), cuja representação gráfica é apresentada na Figura 3. Foi constatado, nas sementes das quatro cultivares, elevação linear da incidência de microrganismos com o retardamento da colheita, fato que corrobora ao mencionado por Marcos Filho (1979). Os gêneros mais frequentes de microrganismos identificados nas sementes das quatro cultivares de soja foram Aspergillus sp., Fusarium sp., Phomopsis spp. e Cercospora kikuchii. Das espécies de Aspergillus identificadas predominaram $A$. flavus e A. niger.

Cerqueira e Popinigis (1981) referiram-se ao nível de vigor das sementes como dependente de aspectos genéticos, fisiológicos, morfológicos, citológicos, mecânicos e microbiológicos, sendo que a condição fisiológica inadequada da semente pode advir da maturação em período desfavorável e ao processo deteriorativo.

Após a época de colheita realizada com 7 dias, percebeuse que os níveis de vigor começaram a diminuir, pois, as sementes de soja já estariam basicamente armazenadas a campo e, portanto, sujeitas às variações de precipitação 
e temperatura (Figura 1A e 1B). Tais condições exercem papel fundamental na qualidade fisiológica das sementes e reduzem, em algumas situações, sua qualidade comercial (Figuras 2 e 4). Lopes (1990), Rosseto e Marcos Filho, (1995), citados por Lopes et al. (2002), têm procurado elucidar os mecanismos que determinam a deterioração das sementes. Entre esses mecanismos, a exposição das sementes à temperatura e à umidade relativa elevadas provoca sérias degenerações no seu metabolismo, desencadeadas pela desestruturação e perda da integridade do sistema de membranas celulares, causadas principalmente pela peroxidação dos lipídeos. Além da perda da compartimentalização celular, a desintegração do sistema de membranas promove descontrole do metabolismo, da água e solutos entre as células e o meio exterior, determinando a queda na viabilidade das sementes.

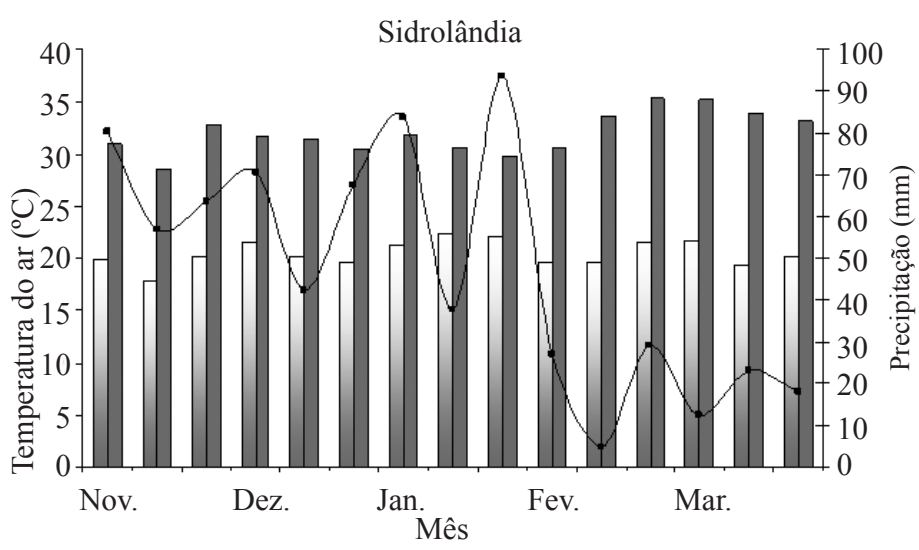

$\varpi$ Temperatura mínima $\square$ Temperatura máxima $\rightarrow$ Precipitação

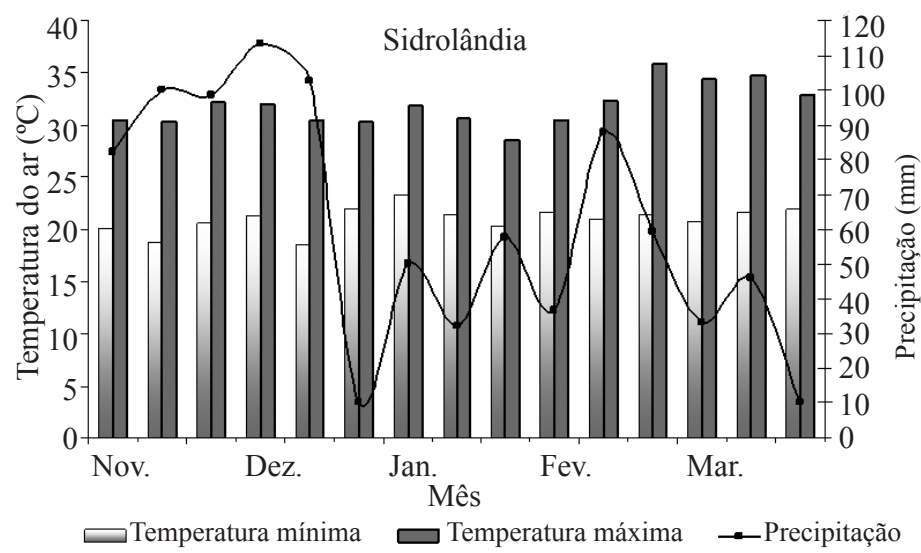

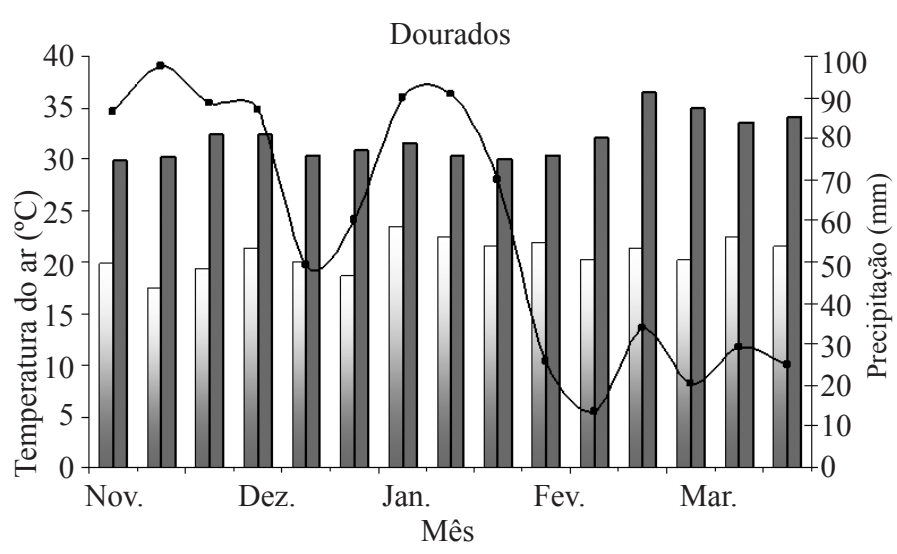

$\square$ Temperatura mínima $\square$ Temperatura máxima $\quad$ — Precipitação

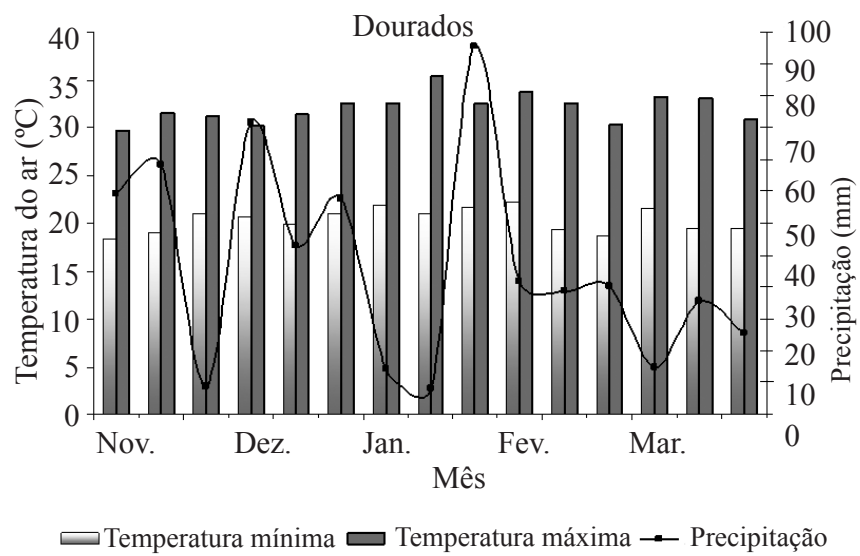

FIGURA 1. Dados de temperaturas mínimas e máximas e de precipitações pluviais, em Sidrolândia e Dourados, MS, de novembro a março, nos anos agrícolas de 2004/05 (A) e 2005/06 (B).

Considerando os dados de porcentagem de germinação e de incidência de microrganismos, influenciados pelo fator isolado localidade de produção, sementes produzidas em Sidrolândia tiveram qualidade fisiológica e sanitária superior as provenientes de Dourados (Tabela 3). O fato indica a localidade de Dourados como a mais desfavorável, comparativamente à Sidrolândia, à produção qualitativa de sementes de soja. Isso, possivelmente, pode estar relacionado às elevadas temperaturas e restrição hídrica mais severa e prolongada na fase reprodutiva das plantas, associadas à ocorrência de precipitações pluviais e concomitante elevação da umidade relativa na maturação (Figura 1), fatores responsáveis por acelerar o processo deteriorativo das sementes. Os resultados obtidos nesse experimento corroboram informações de Pereira et al. (2000), segundo os quais a qualidade fisiológica e sanitária das sementes é influenciada pelo genótipo. 


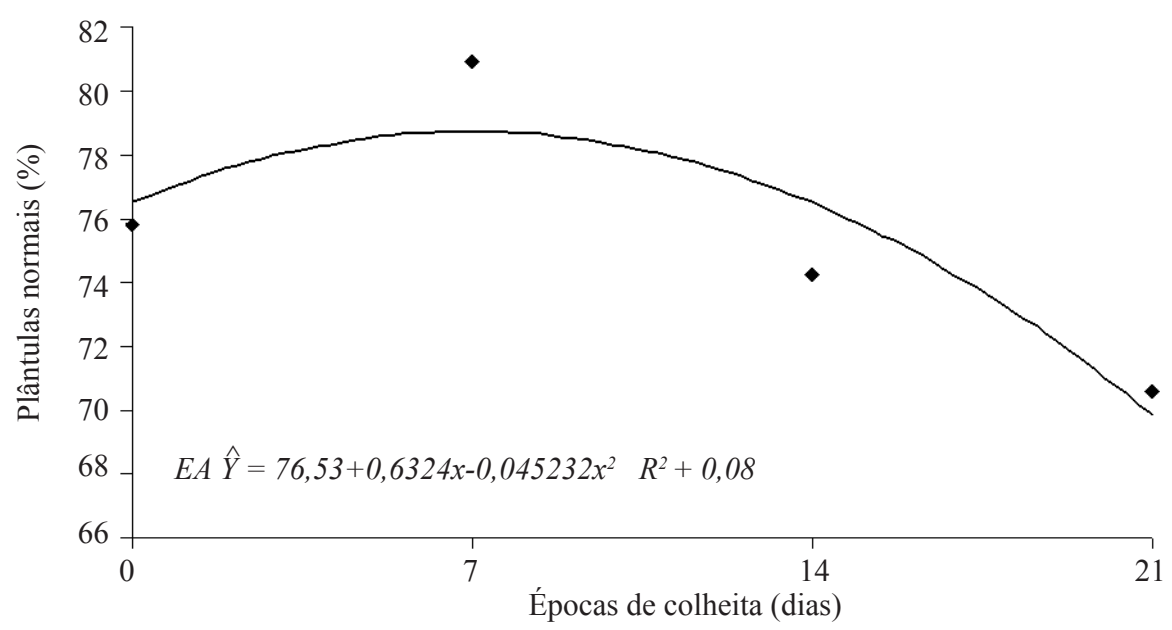

FIGURA 2. Emergência de plântulas de soja em função de quatro épocas de colheita, ano agrícola de 2004/05.

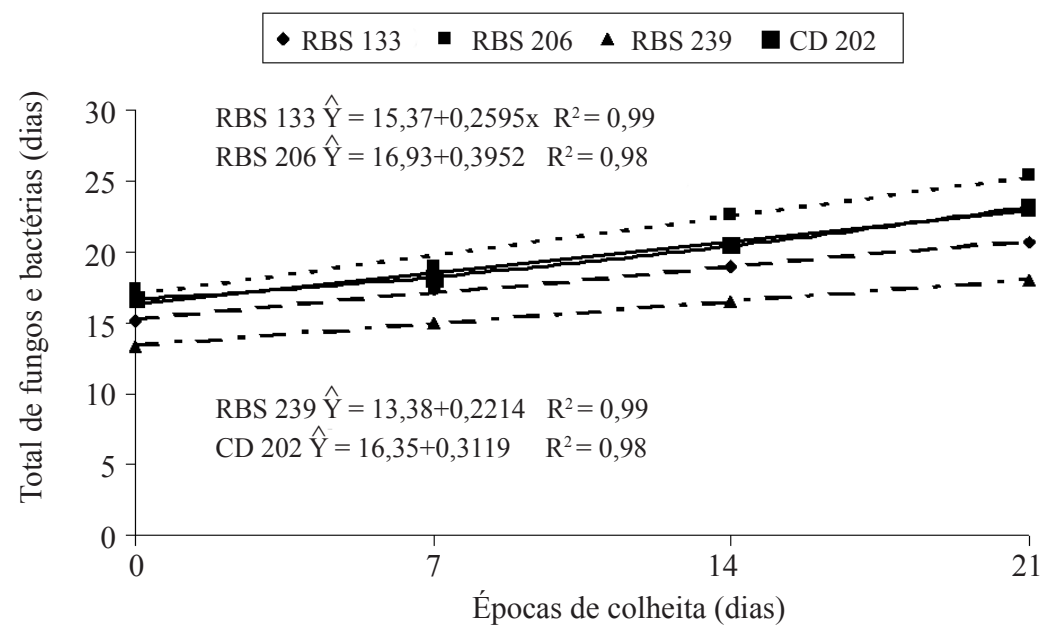

FIGURA 3. Incidência de microrganismos em sementes de quatro cultivares de soja em função de quatro épocas de colheita, ano agrícola de 2005/06.

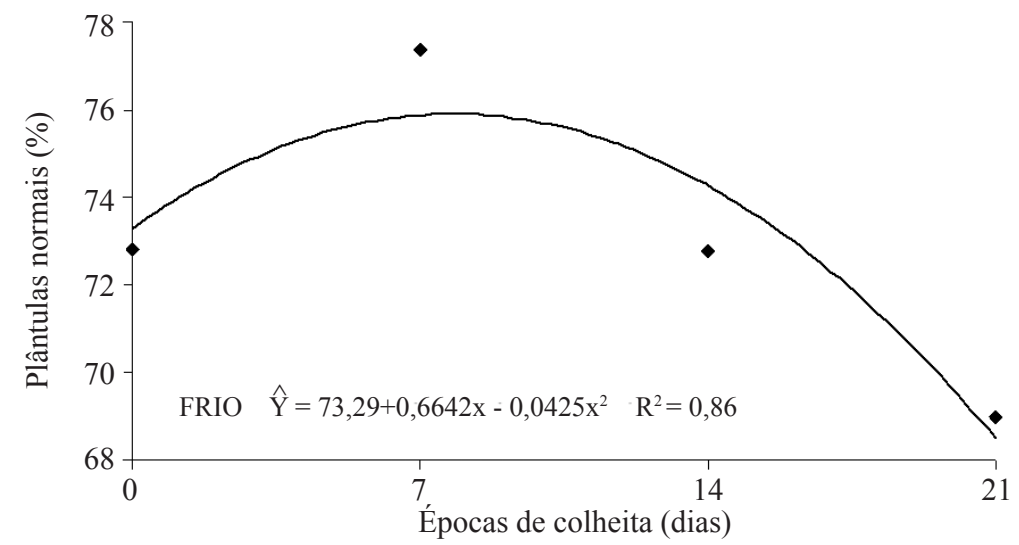

FIGURA 4. Porcentagens de plântulas normais no teste de frio sem solo de sementes de soja em função de quatro épocas de colheita, ano agrícola de 2005/06. 
TABELA 3. Médias de germinação (GER) e de incidência de microrganismos (SAN) em sementes de soja, provenientes de dois locais no Estado do Mato Grosso do Sul, ano agrícola de 2005/06.

\begin{tabular}{lcc}
\hline \multirow{2}{*}{ Local } & \multicolumn{2}{c}{ Características } \\
\cline { 2 - 3 } & GER $(\%)$ & SAN $(\%)$ \\
\hline Sidrolândia & $86 \mathrm{a}^{1}$ & $16 \mathrm{~b}$ \\
Dourados & $81 \mathrm{~b}$ & $20 \mathrm{a}$ \\
\hline Média & 84 & 18 \\
\hline C.V.(\%) Erro 1 & 4,4 & 19,5 \\
\hline C.V.(\%) Erro 2 & 1,4 & 7,0 \\
\hline
\end{tabular}

${ }^{1}$ Médias seguidas de mesma letra, em cada coluna, não difere entre si pelo teste $\mathrm{F}$, a $5 \%$ de probabilidade.

A ocorrência de condições climáticas desfavoráveis como chuvas e altas temperaturas durante as fases de maturação e colheita afetam, além da qualidade fisiológica, a sanidade das sementes (França Neto e Henning, 1984).

Conforme os dados dispostos na Tabela 4 sobre efeito isolado do fator cultivar, sementes da cultivar BRS 239 sobressaíram-se pelo maior porcentual de germinação, não diferindo da cultivar BRS 133 que, por sua vez, foi similar às da CD 202. Sementes da cultivar BRS 206 tiveram resultados inferiores. Resultados semelhantes foram verificados nos testes de envelhecimento acelerado e de emergência de plântulas em areia. Diversos autores citaram a ocorrência de condições que dificultam a obtenção de sementes com qualidade aceitável (Marcos Filho et al., 1985; Keigley e Mullen, 1986) como, por exemplo, temperatura elevada e alta pluviosidade, principalmente no final do ciclo, déficit hídrico na fase de enchimento de grãos e ataque de percevejos.

$\mathrm{Na}$ região sul do Mato Grosso do Sul, de acordo com relatos de Costa et al. (1995), há dificuldades de produção de sementes de boa qualidade, principalmente de cultivares precoces, por causa da ocorrência de chuvas no período próximo da colheita. A cidade de Dourados localiza-se na mesoregião sudoeste e Sidrolândia se localiza na mesoregião Centro norte do Estado. Em Sidrolândia, a precipitação foi superior a Dourados; isto influenciou no desenvolvimento da cultura, principalmente em virtude da deficiência hídrica ter sido mais prejudicial na região de Dourados de um ano para o outro (safra 2004/05 para 2005/2006).
TABELA4. Médias de germinação (GER), de germinação após envelhecimento acelerado (ENV) e de emergência das plântulas em areia (EPA), de sementes de quatro cultivares de soja produzidas no Estado do Mato Grosso do Sul, ano agrícola de 2005/06.

\begin{tabular}{lccc}
\hline \multirow{2}{*}{ Cultivar } & \multicolumn{3}{c}{ Características } \\
\cline { 2 - 4 } & GER (\%) & ENV (\%) & EPA (\%) \\
\hline BRS 133 & $86 \mathrm{ab}^{1}$ & $76 \mathrm{ab}$ & $84 \mathrm{ab}$ \\
BRS 206 & $77 \mathrm{c}$ & $69 \mathrm{~b}$ & $75 \mathrm{c}$ \\
BRS 239 & $89 \mathrm{a}$ & $78 \mathrm{a}$ & $85 \mathrm{a}$ \\
CD 202 & $83 \mathrm{~b}$ & $73 \mathrm{ab}$ & $81 \mathrm{~b}$ \\
\hline Média & 84 & 74 & 84 \\
\hline C.V.(\%) Erro 1 & 4,4 & 4,6 & 1,9 \\
\hline C.V.(\%) Erro 2 & 1,4 & 1,8 & 0,9 \\
\hline
\end{tabular}

${ }^{1}$ Médias seguidas de mesma letra, em cada coluna, não diferem entre si pelo teste de Tukey, a 5\% de probabilidade.

Na Figura 4 estão apresentados os resultados da porcentagem de plântulas normais no teste de frio sem solo que acusou efeito isolado do fator épocas de colheita. A equação de regressão com melhor ajuste foi o modelo quadrático, com ponto de máximo aos 8 dias após o estádio $\mathrm{R}_{7}(75,89 \%)$. Assim, a redução da qualidade fisiológica das sementes com o retardamento de colheita confirma os resultados obtidos no teste de germinação. É reconhecido que a máxima qualidade das sementes de soja é alcançada por ocasião da maturidade fisiológica, coincidindo com o máximo acúmulo de biomassa seca, vigor e germinação (Bewley e Black, 1994). O período de permanência das sementes de soja no campo, após a maturidade fisiológica, é fator importante na deterioração ou, mesmo, na perda de vigor (Braccini et al., 2003a).

\section{CONCLUSÕES}

A cultivar BRS 239 destaca-se quanto à qualidade das sementes, apresentando germinação e vigor superiores.

Melhor qualidade de sementes é obtida com a colheita aos sete dias após o estádio $R_{7}$. Em relação à qualidade sanitária das sementes, à medida que se retarda a época de colheita, a porcentagem total de microrganismos aumenta linearmente para todas as cultivares. 


\section{REFERÊNCIAS}

ALBRECHT, L.P.; BRACCINI, A.L.; SCAPIM, C.A.; AGUIAR, C.G.; ÁVILA, M.R.; STÜLP, M. Qualidade fisiológica e sanitária das sementes sob semeadura antecipada da soja. Scientia Agraria, v.9, n.4, p.445-454, 2008.

BARROS, A.S.R.; DIAS, M.C.L.L.; CICERO, S.M.; KRZYZANOWSKI, F.C. Teste de frio. In: KRZYZANOWSKI, F.C.; VIEIRA, R.D.; FRANÇA NETO, J.B. (eds.). Vigor de sementes: conceitos e testes. Londrina: ABRATES, 1999. Cap.5. p.1-15.

BEWLEY, J. D.; BLACK, M. Seeds: physiology of development and germination. 2.ed. New York: Plenum Press, 1994. 445p.

BRASIL. Ministério da Agricultura e Reforma Agrária. Secretaria Nacional de Defesa Agropecuária. Departamento Nacional de Produção Vegetal. Coordenação de Laboratório Vegetal. Regras para análise de sementes. Brasília, DF: 1992. 365p.

BRACCINI, A.L.; ALBRECHT, L.P.; ÁVILA, M.R.; SCAPIM, C.A.; BIO, F.E.I.; SCHUAB, S.R.P. Qualidade fisiológica e sanitária das sementes de quinze cultivares de soja (Glycine $\max (\mathrm{L}$.) Merrill) colhidas na época normal e após o retardamento da colheita. Acta Scientiarum. Agronomy, v.25, n.2, p.449-457, $2003 \mathrm{a}$.

BRACCINI, A.L.; MOTTA, I.S.; SCAPIM, C.A.; BRACCINI, M.C.L.; ÁVILA, M.R.; SCHUAB, S.R.P. Semeadura da soja no período de safrinha: potencial fisiológico e sanidade das sementes. Revista Brasileira de Sementes, v.25, n.1, p.76-86, 2003 b.

CERQUEIRA, W. P.; POPINIGIS, F. Sementes. In: MIYASAKA, S.; MEDINA, J.C. (Ed.). A soja no Brasil. Campinas: ITAL, 1981. p.711-718.

COODETEC. Cultivares de soja 2006. Cascavel: Coodetec, 2006.

COSTA, N.P; FRANÇA NETO, J.B.; PEREIRA, L.A.G.; HENNING, A.A.; TURKIENICZ, L.; DIAS, M.C. Antecipação de colheitas de sementes de soja através do uso de dessecantes. Revista Brasileira de Sementes, v.5, n.3, p.183-198, 1983.

COSTA, N.P.; FRANÇA NETO, J.B.; HENNING, A. A.; KRZYZANOWSKI, F. C.; CABRAL, N. T.; MENDES, M. C. Efeito da época de semeadura sobre a qualidade fisiológica de semente de soja no Estado de Mato Grosso. Revista Brasileira de Sementes, v.17, n.1, p.107-112, 1995.
EMBRAPA. Sistema brasileiro de classificação dos solos. Brasília, DF, 1999. 412 p.

FARIAS, J.R.B.; NEPOMUCENO, A. L.; NEUMAIER, N. Ecologia da soja. Londrina: Embrapa Soja, 2007. 10p (Embrapa Soja. Circular Técnica, 48).

FRANÇA-NETO, J.B.; HENNING, A.A. Qualidade fisiológica da semente. Londrina: EMBRAPA: CNPSo, 1984. p.5-24. (Embrapa - CNPSo. Circular Técnica, 9).

FRANÇA-NETO, J.B.; KRZYZANOWSKI, F.C.; PÁDUA, G.P.; COSTA, N.P.; HENNING, A. A. Tecnologia para produção de sementes de soja de alta qualidade Série Sementes. Londrina: EMBRAPA SOJA. 2007. 12p. (Circular Técnica, 40).

GARCIA, A.; PÍPOLO, A.E.; LOPES, I.A.N.; PORTUGAL, F.A.F. Instalação da lavoura de soja: Época, Cultivares, Espaçamento e População de Plantas. Londrina: Embrapa Soja, 2007. 10p. (Circular Técnica, 51).

GOULART, A.C.P. Principais fungos encontrados em sementes de soja. In: Fungos em sementes: detecção e importância. EMBRAPA: Dourados, 58p. 1997. (Documento, 11).

HENNING, A. A. Patologia de sementes. Londrina: EMBRAPA-CNPSo, 1994. 43p. (Documentos, 90).

KEIGLEY, P. J.; MULLEN, R. E. Changes in soybean seed quality from high temperature during seed fill and maturation. Crop Science, v.26, n.5, p.1212-1216, 1986.

KRZYZANOWSKI, F.C.; FRANÇA NETO, J.B.; HENNING, A.A. Relato dos testes de vigor disponíveis para as grandes culturas. Informativo ABRATES, v.1, n.2, p.15-50, 1991.

LACERDA, A. L. S.; LAZARINI, E.; SÁ, M. E.; VALÉRIO FILHO, W. V. Armazenamento de sementes de soja dessecadas e avaliação da qualidade fisiológica, bioquímica e sanitária. Revista Brasileira de Sementes, v.25, n.2, p.180-192, 2003.

LOPES, J.C. Germinação de sementes de Phaseolus vulgaris $\mathrm{L}$. após diversos períodos e condições de armazenamento. 1990. 254f. Tese (Doutorado). UNICAMP, Campinas, 1990.

LOPES, J. C.; MARTINS FILHO, S.; TAGLIAFERRI, C.; RANGEL, O. J. P. Avaliação da qualidade fisiológica de sementes de soja produzidas em Alegre-ES. Revista Brasileira de Sementes, v.24, n.1, p.51-58, 2002.

MACHADO, J.C. Patologia de sementes: significado e atribuições. In: CARVALHO, N.M.; NAKAGAWA, J. (Coord.). Sementes: ciência, tecnologia e produção. 3. ed. 
Campinas: Fundação Cargill, 1988. 424p.

MARCOS FILHO, J. Fisiologia de sementes de plantas cultivadas. Piracicaba: FEALQ, 2005. 495 p.

MARCOS FILHO, J. Teste de envelhecimento acelerado. In: KRZYZANOWSKI, F.C.; VIEIRA, R.D.; FRANÇA NETO, J.B. (eds.). Vigor de sementes: conceitos e testes. Londrina: ABRATES, 1999. Cap.3, p.1-24.

MARCOS FILHO, J.; CICERO, S. M.; SILVA, W. R. Avaliação da qualidade das sementes. Piracicaba: FEALQ, 1987. 230 p.

MARCOS FILHO, J.; CARVALHO, R. V. de; CÍCERO, S. M.; DEMÉTRIO, C. G. B. Qualidade fisiológica e comportamento de sementes de soja (Glycine max (L.) Merrill) no armazenamento e no campo. Anais da Escola Superior de Agricultura "Luiz de Queiroz", v.42, p.195249, 1985.

MARCOS FILHO, J. Qualidade fisiológica e maturação de sementes de soja (Glycine max (L.) Merrill). 1979. 180f. Tese (Doutorado em Agronomia) - Escola Superior de Agricultura "Luiz de Queiroz", Universidade de São Paulo, Piracicaba.
NAKAGAWA, J.; MACHADO, J. R.; ROSOLEM, C. A. Efeito da qualidade da semente sobre o estabelecimento da população e outras características da soja. Revista Brasileira de Sementes, v.7, n.2, p.47-62, 1985.

PEREIRA, E. B. C.; PEREIRA, A. V.; FRAGA, A. C. Qualidade de sementes de cultivares precoces de soja produzidas em três épocas. Pesquisa Agropecuária Brasileira, v.35, n.8, p.47-55, 2000.

PRIOLLI, R.H.G.; MENDES-JUNIOR, C.T.; SOUSA, S.M.B.; SOUSA, N.E.A.; CONTEL, E.P.B. Diversidade genética da soja entre períodos e entre programas de melhoramento no Brasil. Pesquisa Agropecuária Brasileira, v.39, n. 10, p.967-975, 2004.

ROSSETO, C.A.V.; MARCOS FILHO, J. Comparação entre os métodos de envelhecimento acelerado e de deterioração controlada para avaliação da qualidade fisiológica de sementes de soja. Scientia Agricola, v.52, n.1, p.123-131, 1995.

Tecnologias de produção da soja - região central do Brasil 2007. Londrina: EMBRAPA Soja: Embrapa Cerrados: Embrapa Agropecuária Oeste, 2006. 225p. (Sistemas de Produção, 11). 